\title{
Characterization and determination of six flavonoids in the ethnomedicine "Dragon's Blood" by UPLC-PAD-MS
}

Tao Yi, Yina Tang, Jianye Zhang, Zhongzhen Zhao, Zhijun Yang and Hubiao Chen*

\begin{abstract}
Background: "Dragon's Blood" (DB) has long been used as an ethnomedicine in China to invigorate blood circulation for the treatment of traumatic injuries, blood stasis and pain. To comprehensively assess the quality of DB medicine, a precise and accurate method that can rapidly separate, characterize and quantify multiple active components of DB is crucial.

Results: An ultra performance liquid chromatography (UPLC) coupled with photodiode array detection (PAD) and electrospray ionization mass spectrometry (ESI-MS) method was developed for characterization and determination of six flavonoids in DB. A comprehensive validation of the developed method was conducted, and confirmed that the method presented good sensitivity, precision and accuracy. All linear regressions were acquired with $R^{2}>0.99$, and the limits of detection ranged from 0.06 to $0.83 \mathrm{ng}$. The relative standard deviation (RSD) values were found to be within the range $1.4-3.8 \%$ for the method repeatability test. Recovery studies for the quantified compounds were found to be within the range $94.2-102.8 \%$ with RSD less than $4.9 \%$. DB samples collected from different geographical regions were analyzed by the present method, and the results demonstrated that the contents of the six flavonoids in DB samples varied significantly. Three major active components among the six flavonoids, namely dracorhodin, (2S)-5-methoxyflavan-7-ol and (2S)-5-methoxy-6-methylflavan-7-ol, are suggested as the index for DB quality evaluation.
\end{abstract}

Conclusions: Overall, the present hyphenation method is highly efficient and reliable, and hence suitable for the characterization and determination of the flavonoids of DB ethnomedicine.

Keywords: Dragon's Blood, Daemonorops draco, UPLC-PAD-MS, Characterization, Quality evaluation

\section{Background}

"Dragon's Blood" (DB), a deep red resin secreted from the fruit of the Daemonorops draco tree, has long been used as an ethnomedicine in China to invigorate blood circulation for the treatment of traumatic injuries, blood stasis and pain $[1,2]$. Flavonoids $[3,4]$ and resin terpenoid acids $[5,6]$ are the main constituents of DB. Currently, the quality evaluation for $\mathrm{DB}$ medicine is based on the content of only one marker compound, namely dracorhodin, which is one of the bioactive compounds identified so far in DB [1].

\footnotetext{
* Correspondence: hbchen@hkbu.edu.hk

School of Chinese Medicine, Hong Kong Baptist University, Hong Kong Special Administrative Region, P. R. China
}

In recent years, pharmacologic studies have demonstrated that DB medicine exerts its clinical effects by inhibiting blood platelet aggregation [2,7], and more components of $\mathrm{DB}$ have been found to be active in this process. For example, it is reported that the raw extract of DB dose-dependently inhibits myocardial ischemia and thrombus formation of the rats, and the coagulation time is extended significantly [8]. (2S)-5-methoxy-6-methylflavan7-ol, a flavonoid isolated from DB, dose-dependently inhibits aggregation of washed rabbit platelets induced by collagen, arachidonic acid and adenosine diphosphate (ADP) [9].

It is widely known that multiple constituents are probably involved in any herb's therapeutic functions, and that the content of a single marker compound cannot accurately reflect the quality of herbal products $[10,11]$. 
Thus, for DB as an herbal medicine, a novel quality evaluation standard based on the contents of multiple active components is needed to comprehensively assess its quality. However, accurate means for qualitative and quantitative analysis of the multiple components simultaneously have not been reported, even though the determination of dracorhodin in DB has been carried out by TLC [12], HPLC [13] and CE [14], respectively. Therefore, a method for the simultaneous characterization and determination of the major active components in herbal medicines in general and DB in particular is still a top priority for accurate quality evaluation.

In the present study, a method coupling ultra-performance liquid chromatography (UPLC) with photodiode array detection (PAD) and electrospray ionization mass spectrometry (ESI-MS) was developed for the characterization and determination of six flavonoids in $\mathrm{DB}$ medicine. The validation results revealed that the developed method is highly efficient and reliable, and hence suitable for qualitative and quantitative analysis of DB samples. Based on the sample assay results, three major active components among the six flavonoids, namely dracorhodin, (2S)-5-methoxyflavan7-ol and (2S)-5-methoxy-6- methylflavan-7-ol, are suggested as the index for quality evaluation of $\mathrm{DB}$ medicine.

\section{Experimental}

\section{Materials}

"Dragon's Blood" (DB) samples were collected from various regions of China. Identity of the samples was confirmed by the authors, and voucher specimens were deposited in the School of Chinese Medicine, Hong Kong Baptist University.

\section{Reagents and chemicals}

Analytical grade methanol (Labscan, Bangkok, Thailand) was used for preparation of standards and sample extraction. Chromatographic grade acetonitrile (Labscan, Bangkok, Thailand), chromatographic grade formic acid (Fluka, Buchs, Switzerland) and deionized water obtained from a Milli-Q water purification system (Millipore, Bedford, MA, USA) were used for preparation of the mobile phase.

The standard compound of dracorhodin perchlorate was purchased from the National Institutes for Food and Drug Control (Beijing, China). 4, 6-dihydroxy-2-methoxy3-methyldihydrochalcone, 4, 6- dihydroxy-2-methoxyv3-methylchalcone, (2S)-5,7-dihydroxy-dihydroflavone, (2S)-5-methoxyflavan-7-ol and (2S)-5-methoxy-6-methylflavan-7-ol were isolated by our laboratory with a purity of more than $98 \%$, and their chemical structures were elucidated by comparing them with published data of ${ }^{1} \mathrm{H}$ and ${ }^{13} \mathrm{C}$ NMR [15-17]. Details of their separation and structural elucidation will be reported elsewhere. Their chemical structures are shown in Figure 1.

\section{Preparation of standard and sample solutions}

The stock solutions of six standard compounds were prepared in methanol and stored in the refrigerator. The working solutions were prepared by appropriate dilution of the stock solutions with methanol, and the resulting concentration ranges are listed in Table 1.

DB sample powder $(0.1 \mathrm{~g})$ was extracted with $10 \mathrm{~mL}$ of methanol by means of sonication at room temperature for $0.5 \mathrm{~h}$. Sampling weight of DB is adjusted if necessary. The operations were repeated once, and the residue was washed with $4 \mathrm{~mL}$ of methanol. Total extracts were combined in a<smiles>CCc1c2ccc(-c3ccccc3)oc-2cc(=O)c1C</smiles>

Dracorhodin (1)<smiles>O=C1C[C@H](c2ccccc2)Oc2cc(O)cc(O)c21</smiles>

(2S)-5,7-Dihydroxydihydroflavone (4)<smiles>CCc1c(C)c(O)cc(O)c1CCC(=O)c1ccccc1</smiles>

4,6-Dihydroxy-2-methoxy-3methyldihydrochalcone (2)

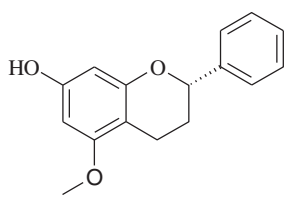

(2S)-5-Methoxyflavan-7-ol (5)<smiles>CCc1c(C)c(O)cc(O)c1/C=C/C(=O)c1ccccc1</smiles>

4,6-Dihydroxy-2-methoxy-3methylchalcone (3)

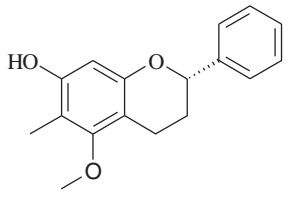

(2S)-5-Methoxy-6methylflavan-7-ol (6)

Figure 1 Chemical structures of the identified components in the UPLC chromatograms. 
Table 1 Linearity curves, LOD and LOQ for six compounds

\begin{tabular}{llcrccc}
\hline Peak & \multicolumn{1}{c}{ Compounds } & Linear equations & Range $(\boldsymbol{\mu g} / \mathbf{m L})$ & $\boldsymbol{R}^{\mathbf{2}}$ & LOD (ng) & LOQ (ng) \\
\hline 1 & Dracorhodin & $y=8580.5 x+8536.8$ & $5-250$ & 0.9998 & 0.48 & 1.60 \\
\hline 2 & 4,6-Dihydroxy-2-methoxy-3- methyldihydrochalcone & $y=6472.4 x+1430.2$ & $1-50$ & 0.9982 & 0.15 & 0.50 \\
\hline 3 & 4,6-Dihydroxy-2-methoxy-3- methylchalcone & $y=6529.5 x-2240.9$ & $1-50$ & 0.9999 & 0.52 & 1.73 \\
\hline 4 & (2S)-5,7-Dihydroxy- dihydroflavone & $y=25710.1 x+14943.4$ & $1-50$ & 0.9989 & 0.06 & 0.20 \\
\hline 5 & (2S)-5-Methoxyflavan-7-ol & $y=989.1 x+16685.5$ & $20-1000$ & 0.9992 & 0.83 & 2.76 \\
\hline 6 & (2S)-5-Methoxy-6-methyl- flavan-7-ol & $y=4098.2 x+14161.0$ & $5-250$ & 0.9991 & 0.21 & 0.70 \\
\hline
\end{tabular}

25-mL volumetric flask, which was filled up to the calibration mark with extraction solvent. The extracts were then filtered through a syringe filter $(0.2 \mu \mathrm{m}$, Alltech, Beerfield, IL, USA). An aliquot of $2 \mu \mathrm{L}$ solution was injected for UPLC-PAD-MS analysis.

\section{UPLC-PAD-MS conditions}

A Waters Acquity ${ }^{\mathrm{TM}}$ ultra performance liquid chromatography (UPLC) system (Waters Corp., Milford, USA) with photodiode array detection (PAD), was hyphenated to a Bruker MicrOTOFQ system by an electrospray ionization (ESI) interface (Bruker Daltonics, Bremen, Germany) for chromatographic and mass spectrometric (MS) analysis. Data analysis was conducted using DataAnalysis software version 4.0 (Bruker Daltonics). For chromatographic separation, a Waters BEH $C_{18}$ column $(1.7 \mu \mathrm{m}, 2.1 \times 100$ $\mathrm{mm})$ with a VanGuard ${ }^{\mathrm{TM}}$ pre-column $\left(\mathrm{BEH}, \mathrm{C}_{18}, 1.7 \mu \mathrm{m}\right.$, $2.1 \times 5 \mathrm{~mm}$ ) was used. The mobile phase consisted of $0.1 \%$ formic acid in water $(\mathrm{A})$ and $0.1 \%$ formic acid in acetonitrile (B) using a gradient program of $25 \%$ (B) in 0-2 $\mathrm{min}$ and $25-55 \%$ (B) in $2-15 \mathrm{~min}$. The solvent flow rate was $0.3 \mathrm{~mL} / \mathrm{min}$, the column temperature was set to $40^{\circ} \mathrm{C}$, and the detection wavelength was $280 \mathrm{~nm}$. The conditions of MS analysis in the positive ion mode were as follows: drying gas (nitrogen), flow rate, $8 \mathrm{~L} / \mathrm{min}$; gas temperature, $180^{\circ} \mathrm{C}$; scan range, $50-1600 \mathrm{~m} / \mathrm{z}$; end plate offset voltage, $-500 \mathrm{~V}$; capillary voltage, $4500 \mathrm{~V}$; nebulizer pressure, 2.5 Bar.

\section{Method validation and sample analysis}

The calibration curve was established by plotting the peak area against the concentrations of the standards with linear regression analysis. The detection (LOD) and limit of quantitation (LOQ) of the quantified constituents were visually evaluated with a signal-to-noise ratio of about 3:1 and 10:1, respectively. Instrumental precision was investigated by repeatedly analyzing the same mixed standard solution six times, and the method repeatability was evaluated by six replicated analyses of the same DB sample. Recovery of all the quantified constituents was determined by samples at different concentration levels using a mixture of standards with 50, 100 and $200 \%$ of the quantified levels of constituents in the DB sample. All DB samples collected from various regions were analyzed using this method.

\section{Results and discussion \\ Optimization of the extraction method and analysis conditions}

Compared to the reflux and soxhlet extraction, sonication extraction was easier, while still satisfactory. The extraction solvent was chosen from methanol, ethanol and their various concentrations of aqueous solution. The results revealed that extraction with absolute methanol produced the highest yield for the desired analytes. Thus, methanol was chosen as the solvent for the sample extraction. Extraction times and cycles were further optimized, and the results demonstrated that exhausted extraction could be achieved when DB sample powder of $0.1 \mathrm{~g}$ was extracted with $10 \mathrm{~mL}$ of methanol by means of sonication for $0.5 \mathrm{~h}$, twice.

The conditions for chromatographic analysis including mobile phase composition, type of column, column temperature and detection wavelength, were optimized based on our previous study [18]. Acetonitrile was found to be preferred over methanol as the mobile phase because it gave better separation for the analytes at a lower column pressure. Mobile phase gradients were compared on a HSS $\mathrm{C}_{18}$ column and $\mathrm{BEH} \mathrm{C}_{18}$ column at different temperatures. The results showed that satisfactory separation could best be obtained by eluting $\mathrm{DB}$ samples on a $\mathrm{BEH} \mathrm{C}_{18}$ column at $40^{\circ} \mathrm{C}$ using a linear gradient of acetonitrile and water within $15 \mathrm{~min}$. A wavelength of $280 \mathrm{~nm}$ was chosen to monitor the analytes after comparing the chromatograms of the DB samples recorded at wavelengths within 190-500 nm. A typical UPLC chromatogram of DB sample at 280 $\mathrm{nm}$ is shown in Figure 2.

The mass spectrometric conditions were optimized in both positive and negative ion modes; the positive ion mode was found to be more sensitive. In order to promote the formation of quasi-molecular ions $[M+\mathrm{H}]^{+}$in MS analysis, $0.1 \%$ formic acid was used in the mobile phase. MS offset voltage was further adjusted to generate characteristic fragments of the six analytes. 


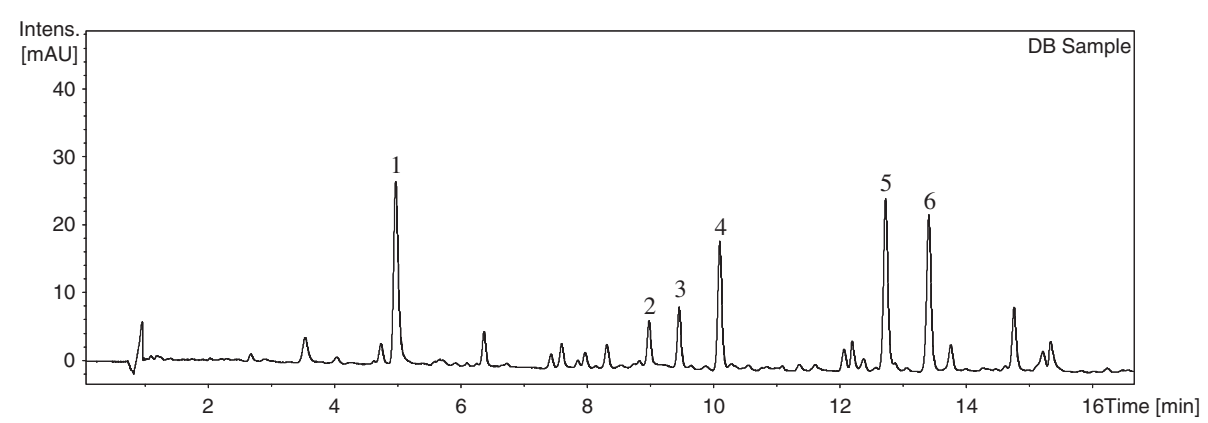

Figure 2 Typical UPLC chromatogram of DB sample using PDA at $280 \mathrm{~nm}$.

\section{ESI-MS characterization of the six flavonoids}

Herbal medicine is a multicomponent system with many unknown components, and the chromatographic peaks often overlap when a sample of an herbal medicine is eluted on a column. The retention time of the analytes can vary between different laboratories, while the UV spectra of the active components and other analogues are greatly similar. Thus, the direct identification of the target compounds merely based on the chromatographic parameters is still a challenge in many cases.

Compared to chromatography, mass spectrometry can provide more exclusive molecular information on the target compounds by elucidating their fragmentation pathways. These MS fragmentation characteristics greatly contribute to identify the active components from the complex mixture of herbal medicine even if the standard compounds are unavailable. Therefore, precise MS characterization of the six flavonoids is necessary in this study.

Based on comparison with chromatograms and MS fragments of standard compounds, six peaks in the DB sample chromatogram were unambiguously identified as dracorhodin (1), 4,6-dihydroxy-2- methoxy-3-methyldihydrochalcone (2), 4,6-dihydroxy-2-methoxy-3-methylchalcone (3), (2S)-5, 7- dihydroxy-dihydroflavone (4), (2S)-5-methoxyflavan-7-ol (5) and (2S)-5-methoxy-6-methylflavan- 7-ol (6). From the results, it is obvious that the major types of constituents in DB are flavonoids, including anthocyanins, chalcones, flavanones and flavans. The extracted ion chromatogram (EIC) MS spectra and the proposed fragmentation pathways of the six flavonoids are shown in Figure 3.

Under the MS conditions, dracorhodin (peak 1) is more stable than other components, and it is not easy for dracorhodin to generate new characteristic fragment ions. Chalcones (peak 2 and peak 3 ) lose a common molecule of $\mathrm{H}_{2} \mathrm{O}(-18 \mathrm{Da})$ forming their $[M+\mathrm{H}]^{+}$ions, while the fragments of $\mathrm{m} / \mathrm{z} 167\left(\mathrm{C}_{9} \mathrm{H}_{11} \mathrm{O}_{3}\right)$ and $\mathrm{m} / \mathrm{z} 105\left(\mathrm{C}_{7} \mathrm{H}_{5} \mathrm{O}\right)$ are the characteristic ions of peak 2 and peak 3 , respectively. Flavanone (peak 4) and flavans (peaks 5 and 6) lose a common molecule of $\mathrm{C}_{8} \mathrm{H}_{8}(-104 \mathrm{Da})$ to generate their characteristic fragment ions of m/z $153\left(\mathrm{C}_{7} \mathrm{H}_{5} \mathrm{O}_{4}\right), \mathrm{m} / \mathrm{z}$
$153\left(\mathrm{C}_{8} \mathrm{H}_{9} \mathrm{O}_{3}\right)$ and $\mathrm{m} / \mathrm{z} 167\left(\mathrm{C}_{9} \mathrm{H}_{11} \mathrm{O}_{3}\right)$, respectively [17]. The detailed elemental composition of the fragments is summarized in Table 2, and the mass errors between the observed and calculated values of molecular weight of the fragments are found to be less than $10 \mathrm{mDa}$. The results demonstrate that the developed UPLC-MS method is specific and precise, and therefore is suitable for the characterization of the flavonoids in DB medicine.

\section{Method validation}

Validation of the developed method was conducted, and the results are summarized in Tables 1 and 3 . Linearity was determined with five data points over the concentration range. For all of the analytes, good linear calibrations were achieved over the selected concentration range with $R^{2}>0.99$. At a signal-to-noise ratio of 3:1, the limits of detection (LOD) of the quantified components were found to be within the range $0.06-0.83 \mathrm{ng}$. The instrumental precision and method repeatability were evaluated, and the relative standard deviation (RSD) values were found to be within the range of 0.8 to $2.5 \%$ for the instrumental precision test and of 1.4 to $3.8 \%$ for the method repeatability test. The accuracy of the method was validated by the determination of recovery. Recovery study was conducted using a DB sample spiked with approximately 50, 100 and $200 \%$ of known amounts of analytes in the samples. The spiked samples were then extracted and quantified in accordance with the established procedures. Triplicate sample analysis was conducted for the determination of recovery at each spiked level. The recoveries of all of the analytes were within the range $94.2-102.8 \%$ with RSD $\leq 4.9 \%$. The results show that the overall procedure is precise and accurate, and therefore is suitable for the quantitative analysis of DB samples.

\section{Sample analysis}

The "Dragon's Blood" (DB) samples collected from different regions were assessed by the present method, and the results are listed in Table 4. From the results two findings emerge. 


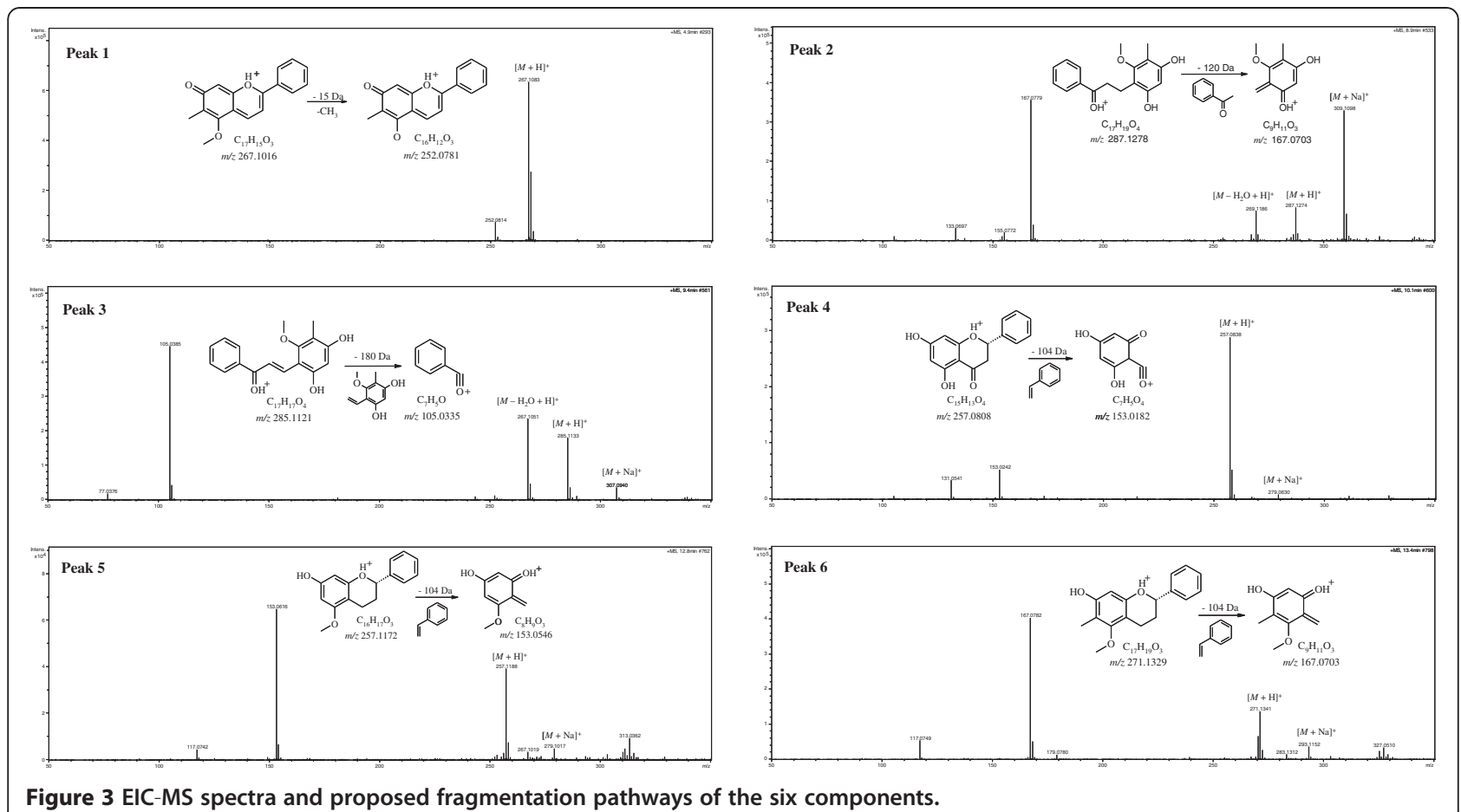

Firstly, there is a significant variation in the contents of the quantified components in DB samples. Such variations may be mainly due to processing of the raw material. According to the literature [19], Daemonorops draco is a plant indigenous to Indonesia and Malaysia, and the resin directly collected from the fruit of Daemonorops draco tree is called raw "Dragon's Blood" (DB). Before being sold in markets and used in clinics, the raw DB is processed to remove fruit pulp residue, and it is shaped by the addition of excipients, such as albane and dammar. However, the

Table 2 Elemental composition of major fragments in the MS spectra

\begin{tabular}{|c|c|c|c|c|c|c|}
\hline Peak & $\mathbf{R T}(\mathbf{m i n})$ & Compounds & Formula & Calculated $(\mathrm{m} / \mathrm{z})$ & Observed $(\mathrm{m} / \mathrm{z})$ & Error (mDa) \\
\hline \multirow[t]{2}{*}{1} & 4.9 & Dracorhodin & $\mathrm{C}_{17} \mathrm{H}_{15} \mathrm{O}_{3}$ & 267.1016 & 267.1083 & 6.7 \\
\hline & & & $\mathrm{C}_{16} \mathrm{H}_{12} \mathrm{O}_{3}$ & 252.0781 & 252.0814 & 3.3 \\
\hline \multirow[t]{4}{*}{2} & 8.9 & 4,6-Dihydroxy-2-methoxy-3-methyldihydrochalcone & $\mathrm{C}_{17} \mathrm{H}_{18} \mathrm{O}_{4} \mathrm{Na}$ & 309.1097 & 309.1098 & 0.1 \\
\hline & & & $\mathrm{C}_{17} \mathrm{H}_{19} \mathrm{O}_{4}$ & 287.1278 & 287.1274 & -0.4 \\
\hline & & & $\mathrm{C}_{17} \mathrm{H}_{17} \mathrm{O}_{3}$ & 269.1172 & 269.1186 & 1.4 \\
\hline & & & $\mathrm{C}_{9} \mathrm{H}_{11} \mathrm{O}_{3}$ & 167.0703 & 167.0779 & 7.6 \\
\hline \multirow[t]{4}{*}{3} & 9.4 & 4,6-Dihydroxy-2-methoxy- 3-methylchalcone & $\mathrm{C}_{17} \mathrm{H}_{16} \mathrm{O}_{4} \mathrm{Na}$ & 307.0941 & 307.0940 & -0.1 \\
\hline & & & $\mathrm{C}_{17} \mathrm{H}_{17} \mathrm{O}_{4}$ & 285.1121 & 285.1133 & 1.2 \\
\hline & & & $\mathrm{C}_{17} \mathrm{H}_{15} \mathrm{O}_{3}$ & 267.1016 & 267.1051 & 3.5 \\
\hline & & & $\mathrm{C}_{7} \mathrm{H}_{5} \mathrm{O}$ & 105.0335 & 105.0385 & 5.0 \\
\hline \multirow[t]{3}{*}{4} & 10.1 & (2S)-5,7-Dihydroxy- dihydroflavone & $\mathrm{C}_{15} \mathrm{H}_{12} \mathrm{O}_{4} \mathrm{Na}$ & 279.0628 & 279.0630 & 0.2 \\
\hline & & & $\mathrm{C}_{15} \mathrm{H}_{13} \mathrm{O}_{4}$ & 257.0808 & 257.0838 & 3.0 \\
\hline & & & $\mathrm{C}_{7} \mathrm{H}_{5} \mathrm{O}_{4}$ & 153.0182 & 153.0242 & 6.0 \\
\hline \multirow[t]{3}{*}{5} & 12.8 & (2S)-5-Methoxyflavan-7-ol & $\mathrm{C}_{16} \mathrm{H}_{16} \mathrm{O}_{3} \mathrm{Na}$ & 279.0992 & 279.1017 & 2.5 \\
\hline & & & $\mathrm{C}_{16} \mathrm{H}_{17} \mathrm{O}_{3}$ & 257.1172 & 257.1188 & 1.6 \\
\hline & & & $\mathrm{C}_{8} \mathrm{H}_{9} \mathrm{O}_{3}$ & 153.0546 & 153.0616 & 7.0 \\
\hline \multirow[t]{3}{*}{6} & 13.4 & (25)-5-Methoxy-6-methyl- flavan-7-ol & $\mathrm{C}_{17} \mathrm{H}_{18} \mathrm{O}_{3} \mathrm{Na}$ & 293.1148 & 293.1152 & 0.4 \\
\hline & & & $\mathrm{C}_{17} \mathrm{H}_{19} \mathrm{O}_{3}$ & 271.1329 & 271.1341 & 1.2 \\
\hline & & & $\mathrm{C}_{9} \mathrm{H}_{11} \mathrm{O}_{3}$ & 167.0703 & 167.0782 & 7.9 \\
\hline
\end{tabular}


Table 3 Precision and accuracy study of the method

\begin{tabular}{|c|c|c|c|c|c|c|}
\hline \multirow[t]{2}{*}{ Peak } & \multirow[t]{2}{*}{ Compounds } & \multicolumn{2}{|c|}{ Precision (RSD \%, $n=6$ ) } & \multicolumn{3}{|c|}{ Accuracy (RSD \%, $n=3$ ) } \\
\hline & & Instrument & Repeatability & Low & Medium & High \\
\hline 1 & Dracorhodin & 1.3 & 1.4 & $102.8(2.2)$ & $96.2(2.5)$ & $98.2(2.3)$ \\
\hline 2 & 4,6-Dihydroxy-2-methoxy-3- methyldihydrochalcone & 0.8 & 2.1 & $94.2(3.2)$ & $94.7(1.8)$ & $95.3(3.4)$ \\
\hline 3 & 4,6-Dihydroxy-2-methoxy-3- methylchalcone & 1.6 & 3.1 & $99.3(2.0)$ & $97.7(3.5)$ & $100.6(2.5)$ \\
\hline 4 & (2S)-5,7-Dihydroxy- dihydroflavone & 0.9 & 2.7 & $102.7(2.8)$ & $96.1(1.9)$ & $96.4(4.9)$ \\
\hline 5 & (2S)-5-Methoxyflavan-7-ol & 2.5 & 3.8 & $99.9(3.8)$ & $101.0(2.0)$ & $99.8(3.7)$ \\
\hline 6 & (2S)-5-Methoxy-6- methylflavan-7-ol & 1.5 & 2.7 & $101.5(4.5)$ & $99.8(2.9)$ & $98.7(4.5)$ \\
\hline
\end{tabular}

cost of DB is high while the cost of the excipients is low. It is hard to tell from appearance how much true DB is in any given sample sold on the market. Hence, there is an attempt to adding more excipients into the $\mathrm{DB}$, and sell it for more profit. The generally low contents of all quantified constituents in some DB samples can be attributed to this reason. On the other hand, this finding confirms the necessity of developing a comprehensive quality evaluation standard based on the quantitation of the active components and on novel analysis technology to ensure the quality of DB medicine.

Secondly, comparison of the contents of the six analytes shows that the total amounts of dracorhodin (peak 1), (2S)-5-methoxyflavan-7-ol (peak 5) and (2S)-5-methoxy-6-methylflavan-7-ol (peak 6) represent about $90 \%$ of the total quantified compounds. It is undoubted that dracorhodin applicable as markers for quality evaluation of $\mathrm{DB}$, due to that it is an identified bioactive component [1]. In recent years, the anti-platelet effects of flavonoids have been confirmed by many reports in the literature [20-22], and laboratory studies suggest that "Dragon's Blood" species exert their clinical effects by inhibiting blood platelet aggregation [2]. The anti-platelet effect of
(2S)-5-methoxyflavan-7-ol and (2S)-5-methoxy-6-methylflavan-7-ol have been reported $[9,23]$, and the underlying mechanism for anti-platelet activity of (2S)-5-methoxy-6methylflavan-7-ol was related to inhibition of TXA2 formation via the inhibition of COX. Based on our research results and these reports, we believe that dracorhodin, (2S)-5-methoxyflavan-7-ol and (2S)-5-methoxy-6-methylflavan-7-ol can well represent the active flavonoids of DB to be responsible for the clinical effects of "Dragon's Blood" against blood stasis.

Therefore, to reflect the roles of multiple compounds for the therapeutic functions, dracorhodin, (2S)-5-methoxyflavan7-ol and (2S)-5-methoxy-6-methylflavan-7-ol should be chosen as analytical markers for a more comprehensive quality evaluation of DB medicine. The present hyphenation method could meet this need, making a simultaneous analysis of the three active components in a single run possible.

\section{Conclusions}

A UPLC-PAD-MS method was developed for the simultaneous analysis of six flavonoids in the ethnomedicine "Dragon's Blood" (DB). The six components were characterized by

Table 4 Contents of six compounds in the DB samples

\begin{tabular}{|c|c|c|c|c|c|c|c|}
\hline \multirow[t]{2}{*}{ No. } & \multirow{2}{*}{$\begin{array}{l}\text { Purchase } \\
\text { location }\end{array}$} & \multicolumn{6}{|c|}{ Contents of six compounds $(\mathbf{m g} / \mathbf{g}, n=3$ ) } \\
\hline & & $\begin{array}{l}\text { Dracorhodin } \\
\text { (1) }\end{array}$ & $\begin{array}{c}\text { 4,6-Dihydroxy-2 } \\
\text {-methoxy-3- } \\
\text { methyldihydrochalcone } \\
\text { (2) }\end{array}$ & $\begin{array}{l}\text { 4,6-Dihydroxy-2- } \\
\text { methoxy-3- } \\
\text { methylchalcone } \\
\text { (3) }\end{array}$ & $\begin{array}{c}\text { (2S)-5,7- } \\
\text { Dihydroxy- } \\
\text { dihydroflavone } \\
\text { (4) }\end{array}$ & $\begin{array}{l}\text { (2S)-5- } \\
\text { Methoxy } \\
\text { flavan-7-ol } \\
(5)\end{array}$ & $\begin{array}{l}\text { (2S)-5-Methoxy-6- } \\
\text { methylflavan-7-ol } \\
(6)\end{array}$ \\
\hline DB1 & Hong Kong & 1.69 & 0.78 & 1.14 & 0.49 & 24.79 & 4.98 \\
\hline DB2 & Hong Kong & 0.93 & 1.11 & 0.46 & 0.47 & 21.01 & 6.60 \\
\hline DB3 & Hong Kong & 4.76 & 0.98 & 0.28 & 0.24 & 13.07 & 4.38 \\
\hline DB4 & Hong Kong & 0.77 & 0.21 & 0.06 & 0.02 & 4.18 & 3.03 \\
\hline DB5 & Hong Kong & 0.41 & 0.93 & 0.13 & 0.11 & 7.66 & 4.42 \\
\hline DB6 & Beijing & 15.71 & 10.58 & 4.22 & 2.65 & 87.94 & 23.88 \\
\hline DB7 & Chengdu & 16.46 & 5.69 & 1.36 & 1.21 & 59.32 & 20.01 \\
\hline DB8 & Chengdu & 8.49 & 2.90 & 1.27 & 0.85 & 42.67 & 11.81 \\
\hline DB9 & Chengdu & 2.64 & 7.85 & 0.26 & 1.44 & 58.78 & 13.70 \\
\hline DB10 & Tianjin & 30.24 & 17.78 & 1.84 & 3.98 & 167.64 & 47.38 \\
\hline DB11 & Tianjin & 3.04 & 4.63 & 1.96 & 1.30 & 41.78 & 23.48 \\
\hline DB12 & Jilin & 22.10 & 13.66 & 3.19 & 13.58 & 83.23 & 58.80 \\
\hline
\end{tabular}


online ESI-MS, and then were quantified by PAD. With respect to already existing methods, the present hyphenation procedure is highly efficient and reliable, and hence suitable for qualitative and quantitative analysis of DB samples. Based on the determination results, it is suggested that three major active components among the six flavonoids, namely dracorhodin, (2S)-5-methoxyflavan-7-ol and (2S)-5-methoxy-6- methylflavan-7-ol, be used as the index for quality evaluation of $\mathrm{DB}$ medicine.

\section{Abbreviations}

UPLC: Ultra performance liquid chromatography; PAD: Photodiode array detection; ESI: Electrospray ionization; MS: Mass spectrum; TLC: Thin layer chromatography; HPLC: High performance liquid chromatography; CE: Capillary electrophoresis; TXA2: Thromboxane A2; COX: Cyclooxygenase.

\section{Competing interests}

The authors declare that they have no competing interests.

\section{Authors' contributions}

HBC initiated and all authors designed the study. The sample extraction was conduct by YNT and JYZ. The method developments were conducted by TY who drafted the manuscript. All authors contributed to data analysis, read and approved the final manuscript.

\section{Acknowledgements}

This research was funded by the Faculty Research Grant of Hong Kong Baptist University (FRG2/10-11/080)

Received: 10 September 2012 Accepted: 8 October 2012

Published: 10 October 2012

\section{References}

1. State Pharmacopoeia Committee: Pharmacopoeia of the People's republic of china 2010. Beijing: China Medical Science and Technology Press; 2010:133.

2. The Editorial Committee: Materia medica of china (volume 8). Shanghai: Shanghai Science and Technology Publishing House; 1999:455.

3. Arnone A, Nasini G, Merlini L: Constituents of dragon's blood. Part 4. Dracoflavan a, a novel secotri flavanoid. J Chem Soc Perkin 1 1990, 10:2637-2640

4. Shen CC, Tsai SY, Wei SL, Wang ST, Shieh BJ, Chen CC: Flavonoids isolated from draconis resina. Nat Prod Res 2007, 21:377-380

5. Piozzi F, Passannanti S, Paternostro MP, Nasini G: Diterpenoid resin acids of daemonorops Draco. Phytochemistry 1974, 13:2231-2233.

6. Nasini G, Piozzi F: Pterocarpol and triterpenes from daemonorops Draco. Phytochemistry 1981, 20:514-516.

7. Lu H, Teng JB, Wu HE: Advances in the studies of Dragon's blood produced in china. Chin J of Ethnomed and Ethnopharm 2003, 12:264-267.

8. Zhang XY, Chen SB, Hu HW, Xu ZR, Wang JM: Study on equivalence of Dragon's blood and resina draconis on the cardiovascular system. China Pharm 2009, 12:726-728.

9. Tsai WJ, Hsieh HT, Chen CC, Kuo YC, Chen CF: Characterization of the antiplatelet effects of (2S)-5-methoxy-6-methylflavan-7-ol from draconis resina. Eur J Pharmacol 1998, 346:103-110.

10. Yi T, Chen HB, Zhao ZZ, Jiang ZH, Cai SQ, Wang TM: Identification and determination of the major constituents in the traditional Uighur medicinal plant saussurea involucrata by LC-DAD-MS. Chromatographia 2009, 69:537-542.

11. Cheng YQ, Zhang YX, Qi SD, Chen HL, Chen XG: Simultaneous separation and analysis of two bioactive xanthones in the Tibetan medicinal plant gentianopsis paludosa (hook. f.) Ma by micellar electrokinetic capillary chromatography. Acta Chromatogr 2010, 22:637-650.

12. Wang YH, Mu SY, Wang W, Hang G: Determination of dracorhodin in xuejie from different places by TLC-scanning method. Lishizhen Med Mater Med Res 2000, 11:1073-1074.

13. Huang MH, Yong KL: Comparison daemonorops Draco BI. With dracaena cochinchinensis (lour.) S.C. Chen by HPLC fingerprints analysis. J Shanghai University (Nat Sci Ed) 2001, 7:326-340.
14. Gong WJ, Cao YH, Wang Y: Differentiation of resina draconis from sanguis draconis by CE. Chromatographia 2007, 66:767-771.

15. Mu Q, Li CM, He YN, Sun HD, Zheng HL, Lu Y, Zheng QT, Wu N, Jiang RW: Three new styrylpyrones from goniothalamus leiocarpus. Chin Chem Lett 1999, 10:135-138.

16. Tsai SY: Studies on the constituents of phyllodium pulchellum and draconis resina. Master thesis.: Chung Yuan Christian University, department of Chemistry; 2005.

17. Shi JM: Studies on the bioactive components of Dragon's blood from $D$. Draco. Master thesis.: Zhejiang University, Faculty of Science; 2010.

18. Yi T, Chen HB, Zhao ZZ, Yu ZL, Jiang ZH: Comparison of the chemical profile and anti-platelet aggregation effects of two "Dragon's blood" drugs used in traditional Chinese medicine. J Ethnopharmacol 2011, 133:796-802.

19. Hu SF: Authentication of medicinal material "Dragon's blood". Cent South Pharm 2008, 6:766-767.

20. Afifi FU, Aburjai T: Antiplatelet activity of varthemia iphionoides. Fitoterapia 2004, 75:629-633.

21. Ko HH, Hsieh HK, Liu CT, Lin HC, Teng CM, Lin CN: Structure-activity relationship studies on chalcone derivatives: potent inhibition of platelet aggregation. J Pharm Pharmacol 2004, 56:1333-1337.

22. Wang AM, Zhang FK, Huang LF, Yin XP, Li HF, Wang QY, Zeng ZW, Xie T: New progress in biocatalysis and biotransformation of flavonoids. $J$ Med Plants Res 2010, 4:847-856.

23. Gupta D, Bleakley B, Gupta RK: Dragon's Blood: botany, chemistry and therapeutic uses. J Ethnopharmacol 2008, 115:361-380.

doi:10.1186/1752-153X-6-116

Cite this article as: Yi et al:: Characterization and determination of six flavonoids in the ethnomedicine "Dragon's Blood" by UPLC-PAD-MS.

Chemistry Central Journal 2012 6:116.

Publish with ChemistryCentral and every
scientist can read your work free of charge
"Open access provides opportunities to our
colleagues in other parts of the globe, by allowing
anyone to view the content free of charge."
W. Jeffery Hurst, The Hershey Company.
- available free of charge to the entire scientific community
- peer reviewed and published immediately upon acceptance
- cited in PubMed and archived on PubMed Central
- yours - you keep the copyright
submit your manuscript here:
http://www.chemistrycentral.com/manuscript/

